\title{
NUMERICAL SIMULATION OF EFFECT OF FRICTION DIRECTIONALITY ON FORMING OF ANISOTROPIC SHEETS
}

\author{
Trzepiecinski, T. ; Lemu, H. G. ${ }^{* *} \&$ Fejkiel, R. ${ }^{* * *}$ \\ * Rzeszow University of Technology, Department of Materials Forming and Processing, \\ Al. Powstancow Warszawy 12, 35-959 Rzeszow, Poland \\ ** Faculty of Science and Technology, University of Stavanger, N-4036 Stavanger, Norway \\ ${ }^{* * *}$ School of Higher Vocational Education in Krosno, Rynek 1, 38-400 Krosno, Poland \\ E-Mail: tomtrz@prz.edu.pl, hirpa.g.lemu@uis.no,rfejkiel@wp.pl
}

\begin{abstract}
The anisotropy of frictional resistances is often omitted in finite element method (FEM) based numerical modelling of industrial processes of sheet metal forming. The aim of this paper is to analyse the effect of anisotropy of frictional phenomena on the formability of drawpieces. As a benchmark experiment, the formability of cylindrical cups is carried out, and as a benchmark material the deep drawing quality (DDQ) steel sheets are used. The effect of friction phenomena on the formability of cylindrical cups is studied using finite element based program ABAQUS/Standard 3DExperience R2016x HF2. The results of predicted location and height of ears allow concluding that material and frictional anisotropy of sheet metals are the main factors that determine high conformity of the finite element based numerical simulation results with the experiments. Comparison of numerical results demonstrates great potential of Hill yield criterion incorporated with the anisotropic friction model in accurate prediction of earing.

(Received in February 2017, accepted in June 2017. This paper was with the authors 2 weeks for 1 revision.)
\end{abstract}

Key Words: ABAQUS, Finite Element Method, Friction Anisotropy, Sheet Metal Forming

\section{INTRODUCTION}

Sheet metal forming is a widely used process in manufacturing complex shaped parts such as airplane fuselages, door panels, turbine engine struts and elements of combustion systems of turbine engines and auto-bodies [1,2]. The conventional sheet metal forming process that uses metallic dies becomes valuable method in manufacturing of these products. Different kinds of metal alloys are used in the manufacturing of aircraft components, e.g. magnesium, aluminium, titanium, stainless steel and nickel-chromium alloys.

Most of metal sheets manufactured by rolling process exhibit different mechanical properties according to the rolling direction of the sheet $[3,4]$. Mechanical properties of sheet materials differ depending also on the crystallography [5]. The rolled sheet exhibits also directional topography that influences the effectiveness of lubrication and frictional resistances. The anisotropy of mechanical properties of the sheets is characterized by coefficients of anisotropy: normal and planar. Normal anisotropy $r$ (Lankford value) is an indication of resistance to the thinning of a material and is defined as the ratio of transverse strain to thickness strain at the uniform elongation region [6]. If the $r$-value is equal to 1 , the material is considered to be isotropic otherwise it exhibits anisotropic properties. The planar anisotropy coefficient $\Delta r$ is a measure of the variation of $r$-value with an angle from the rolling direction. Planar anisotropic properties in the yield stress and the $r$-value are commonly measured using the simple tension test [7]. Improvement of drawability of anisotropic sheets can be achieved by close control of crystallographic texture in the sheet metal [8].

There are two main phenomena which limit the drawability of sheets in sheet metal forming. Earing behaviour is the first phenomena and it occurs when the drawing ratios are 
different at different directions in deep drawing. It is well known that earing is usually seen on the upper edges of the cups drawpieces. The second one is the fracture of the sheet in the vicinity of punch edge due to exceeding the limited value of sheet thinning. To achieve the required formability, it is highly important to understand the quantitative relation between the texture and the anisotropy of the $r$-value. In addition, controlling the texture in the manufacturing process is essential [9]. Furthermore, the springback behaviour should be taken into account to compensate the drawpiece shape deviation from the nominal shape [10].

To model and analyse complex phenomena in sheet forming, the finite element (FE) method is widely used [4, 11]. Applying numerical simulation in sheet metal forming has many advantages including the fact that it allows prediction of the forming defects and provides a better knowledge of the deformed shape, stress and strain distribution and punch loading. For instance, Abed-Meraim et al. [12] have conducted a quasi-static and dynamic simulation of thin 3D structures in deep drawing process. When the metal is subjected to forming, the hardening relationship and the associated flow rule need to be based on an anisotropic yield criterion. Thus, defining the anisotropic yield criteria is one of the central issues in the analysis of sheet metal forming. Several yield criteria for anisotropic sheets are developed. The most widespread are the Hill (1948) [13] and Hosford (1972) [14] criteria. Hill (1948) [13] criterion is a generalization of the Huber-Mises-Hencky criterion [15]. The investigations of Tikhovskiy [16] indicate that Hill (1948) [13] criterion and its modifications are the most often used for anisotropic model description of steel sheets.

Wrinkling is a form of local buckling of sheet metals when forming by excessive compressive stresses [17]. A numerical study on the influence of crystallographic texture on the earing behaviour of low carbon steel during the cup drawing is carried out by Raabe et al. [18]. As the texture component crystal plasticity finite element method is based on crystal plasticity, it not only accounts correctly for the anisotropy due to the starting texture of the material, but it also includes the change of anisotropy due to texture evolution during the forming operation [19]. To minimize earing the optimum blank geometry can be developed based on the numerical simulations [20]. The study of Habraken and Duchene [21] presents reviews of state of the art numerical models in sheet metal forming analysis dealing with mechanical anisotropy resulting from crystallographic texture.

Many conducted works, for example, Wang et al. [22], confirm that friction phenomena influences formability of sheets and the quality of drawpiece. Among many factors influencing frictional phenomena, the most important are: sheet and die topography and surface roughness, sliding velocity, contact pressure, blank and tool materials, and forming temperature [23, 24]. Ajayi et al. [25] experimentally evaluated the effect of surface texture and sheet topography induced in rolling process on the frictional behaviour of sheets.

The anisotropy of frictional resistances is often omitted in FEM simulation of sheet metal forming processes. Most of authors assumed isotropy of frictional phenomena. So, the aim of this paper is to analyse the effect of frictional anisotropy on the formability of cylindrical cups. The effect of friction phenomena on the formability of cylindrical cups is studied experimentally and based on the finite element based program ABAQUS/Standard 3DExperience R2016x HF2.

\section{MATERIAL AND METHODS}

To confirm effectiveness of proposed approach, the deep drawing quality (DDQ) steel is assumed as a benchmark. The mechanical properties of sheet samples (Table I) were determined using tensile test carried out in the universal testing machine. The test specimens were cut at an angle of $0^{\circ}, 45^{\circ}$ and $90^{\circ}$ with respect to the rolling direction of the sheet metal. The main mechanical parameters determined through tensile tests are: the yield stress $R_{p 0.2}$, 
ultimate tensile strength $R_{m}$, elongation $A_{50}$, coefficient of normal anisotropy $r$ (Lankford's coefficient), and strain hardening parameters such as the hardening exponent $n$ and hardening coefficient $K$ used in Hollomon equation:

$$
\sigma=K \cdot \varepsilon^{n}
$$

where: $\sigma$ is the true stress and $\varepsilon$ is the true strain.

The $\sigma(\varepsilon)$ curve represented by Eq. (1) describes the hardening properties of the material. It also holds that $n$ is a measure of the stretch formability of the material.

Table I: Mechanical properties of the steel sheets.

\begin{tabular}{|c|c|c|c|c|c|c|c|}
\hline Sample orientation & $\boldsymbol{R}_{\boldsymbol{p 0 . 2}}(\mathrm{MPa})$ & $\boldsymbol{R}_{\boldsymbol{m}}(\mathrm{MPa})$ & $\boldsymbol{A}_{\mathbf{5 0}}$ & $\boldsymbol{K}(\mathrm{MPa})$ & $\boldsymbol{n}$ & $\boldsymbol{r}$ & \multirow{2}{*}{$\boldsymbol{r}$} \\
\hline $0^{\mathbf{0}}$ & 162 & 310 & 0.42 & 554 & 0,21 & 1.55 & \\
& 163 & 322 & 0.41 & 542 & 0.20 & 1.27 & \multirow{2}{*}{0.34} \\
\hline $45^{\mathbf{0}}$ & 168 & 312 & 0.41 & 530 & 0.21 & 1.67 & \\
\hline average & 164 & 316.5 & 0.4125 & 542 & 0.205 & 1.44 & - \\
\hline
\end{tabular}

The coefficient of normal anisotropy is determined by uniaxial tensile tests on sheet specimens in the form of a strip. The coefficient of normal anisotropy $r$ is defined by Eq. (2):

$$
r=\frac{\varepsilon_{22}}{\varepsilon_{33}}
$$

where $\varepsilon_{22}$ and $\varepsilon_{33}$ are strains in the width and thickness directions, respectively. If the value of $r$-coefficient is greater than 1, the width strains are dominant. On the other hand $(r<1)$ the thickness strains will dominate. The value of $r$-coefficient is 1 in the case of an isotropic material. The Eq. (2) can be rewritten in the form:

$$
r=\frac{w}{w_{0}} / \frac{g}{g_{0}}
$$

where $g_{0}$ and $g$ are the initial and final thickness, while $w_{0}$ and $w$ are the initial and final width of the specimen, respectively.

The average values of $r$-coefficient for different directions in the plane of sheet metal represents the average coefficient of normal anisotropy $\bar{r}$ which is determined based on the $r$ values at specimens cut along three directions in the plane of the sheet metal $\left(0^{\circ}, 45^{\circ}, 90^{\circ}\right)$ :

$$
\bar{r}=\frac{r_{0}+2 r_{45}+r_{90}}{4}
$$

Variation of the normal anisotropy with the angle to the rolling direction is given by the coefficient of planar anisotropy:

$$
\Delta r=\frac{r_{0}+r_{90}-2 r_{45}}{2}
$$

The $\Delta r$-value is related to the earing amplitude of drawn cups. If the value of the anisotropy coefficient is the same along all the directions in the sheet plane, the earing phenomenon is not observed. Tendency to earing during deep drawing is a function of $\Delta r-$ value. If the value of $\Delta r$ is positive then ears are formed in the direction of sheet rolling and in the direction perpendicular to rolling direction. In contrast, if the $\Delta r$ is lower than 0 then the ears occur at the angle of $45^{\circ}$ according to the sheet rolling direction.

The value of the tensile parameters listed in Table I $\left(R_{p 0,2}, R_{m}, A_{50}, K, n\right)$ has been averaged according to the formulae:

$$
x_{\text {ave }}=\frac{x_{0}+2 x_{45}+x_{90}}{4}
$$

where the subscripts refer to specimen orientation.

Taylor Hobson Surtronic 3+ instrument was used to measure the surface roughness. The standard 2D parameters determined by this measurement are selected based on the literature 
review. The first selected parameter is the roughness average $R a$, which is the basic industrial parameter describing the surface topography of the sheets. Furthermore, according to Sedlaček et al. [26] the most suitable parameters to describe the tribological phenomena occurring during the sheet metal forming are kurthosis $R k u$ and skewness $R s k$. The values of the surface parameter were measured before the friction tests at $30^{\circ}$ between both the rolling and transverse direction. The measurements have confirmed that steel sheets are characterized by the anisotropy of surface topography. The directional surface topography of tested sheet determined using Talysurf CCI Lite 3D optical profiler is presented in Fig. 1.

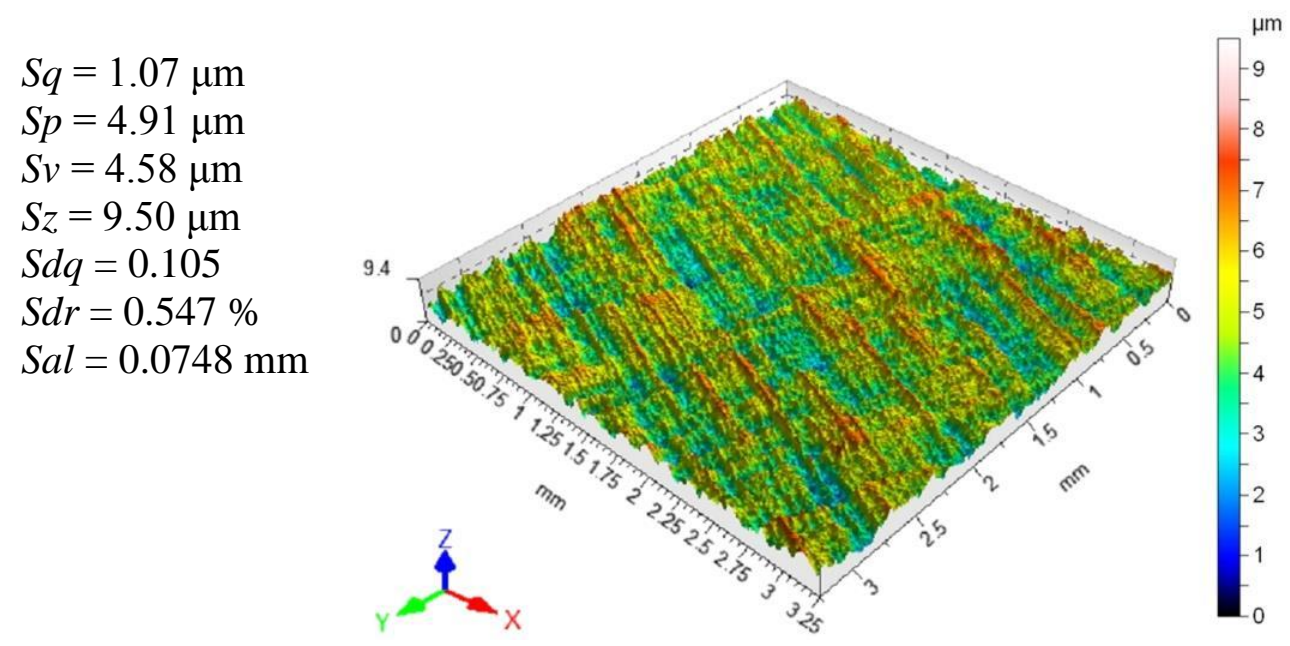

Figure 1: The values of basic roughness parameters and surface topography of tested sheet.

Table II: Selected surface roughness parameters for tested steel sheet.

\begin{tabular}{|c|c|c|c|c|c|c|}
\hline \multirow{2}{*}{$\begin{array}{c}\text { Angle of } \\
\text { measurement }\end{array}$} & \multicolumn{4}{|c|}{$\boldsymbol{R} \boldsymbol{a}(\mu \mathrm{m})$} & \multicolumn{3}{c|}{$\boldsymbol{R k} \boldsymbol{u}$} & \multicolumn{2}{c|}{ Dsk } \\
\cline { 2 - 7 } & \multicolumn{6}{|c|}{ Direction of measurement } \\
\hline $0^{\circ}$ & 1.23 & 1.61 & 2.56 & 2.37 & 0.32 & 0.16 \\
\hline $30^{\circ}$ & 1.27 & 1.49 & 2.43 & 2.32 & 0.19 & 0.19 \\
\hline $60^{\circ}$ & 1.33 & 1.37 & 2.22 & 2.39 & 0.13 & 0.22 \\
\hline $90^{\circ}$ & 1.61 & 1.23 & 2.37 & 2.56 & 0.11 & 0.25 \\
\hline
\end{tabular}

The CSM Instruments pin-on-disk tribometer was used to determine friction properties of the steel sheet. This measuring tool conforms to both ASTM G99 and DIN 50324 designation according to which the friction coefficient may also be determined. In tribometer, the test sample is loaded by a pin with a precisely known force. The pin is mounted on a stiff lever, designed as a frictionless force transducer. To realize dry friction conditions both rolls and sheet specimens were degreased using acetone. A diagram of the pin-on-disk tribometer used in frictional experiments is shown in Fig. 2. A 6-mm-diameter pin was held by a collet in an arm supported on two axes. Disk specimens were $50 \mathrm{~mm}$ in diameter and the initial thickness was $1 \mathrm{~mm}$. They were fastened to the flat end of a 25.4-mm-diameter horizontal shaft of a precision spindle, and thus the disk rotated in a vertical plane. Steel weights attached to the pin holder were used to get three normal forces with value of 6,9 and $12 \mathrm{~N}$.

The value of the friction coefficient $\mu$ is determined according to the expression given in Eq. (7):

$$
\mu=\frac{F_{T}}{F_{N}}
$$

where: $F_{T}$ - friction force, $F_{N}$ - normal force. 


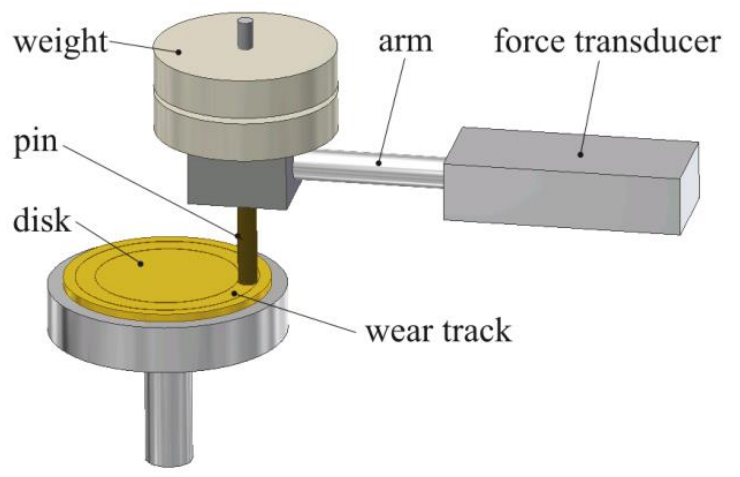

Figure 2: The general chart of the measurement station.

The trend of variation of the friction coefficient during the first registered sample rotation confirms that steel sheets are characterized by the anisotropy of tribological properties (Fig. 3). Friction anisotropy on a given surface has to be clearly distinguished from friction anisotropy for different perpendicular orientations between the pin and the surface. To simplify the analyses of the changes of friction coefficient with respect to the sample rotation, a scratch on sample surface was marked at a position of $0^{\circ}$ corresponding to the sheet rolling direction. Due to this there is a difference between the friction coefficient for orientation $0^{\circ}$ and after full rotation $360^{\circ}$ (Fig. 3). There exists two maxima points within a $360^{\circ}$ rotation and they correspond nearly to the transverse of the rolling direction. The frictional track is unlimited in tribometer test.

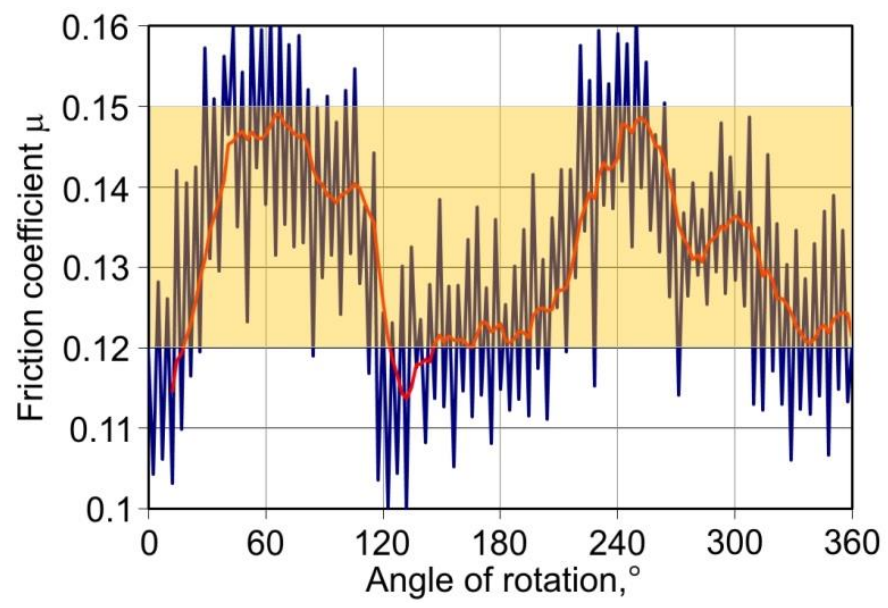

Figure 3: Friction coefficient values as a function of measurement orientation $\left(^{\circ}\right)$ according to the rolling direction for DDQ steel sheet, normal force $9 \mathrm{~N}$, dry friction conditions.

\section{STAMPING PROCEDURE}

In this experiment, stamping of cylindrical cups has been performed. The pictorial and schematic views of the stamping tool are presented in Figs. $4 \mathrm{a}$ and $\mathrm{b}$ respectively. The die is a flat surface with a hole of diameter of $32.3 \mathrm{~mm}$. The cylindrical punch had a diameter of 30 $\mathrm{mm}$. The disk with a diameter of $54 \mathrm{~mm}$ was stamped. The sheet thickness was $1 \mathrm{~mm}$ and the die set is constructed of cold-tool steel. The cups were drawn in dry friction conditions and a hydraulic test machine with forming speed of $0.8 \mathrm{~mm} / \mathrm{s}$ at a room temperature was used. In order to ensure a uniform distribution of the blank holder force, the specimens were carefully positioned at the centre of the die. The applied blank holder force was then determined experimentally by trial-and-error method and kept constant at $2 \mathrm{kN}$ throughout the drawing process. 
a)

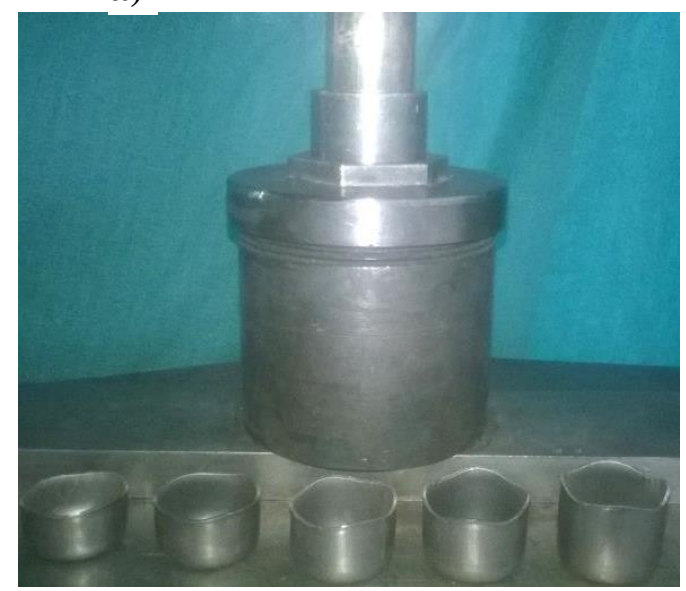

b)

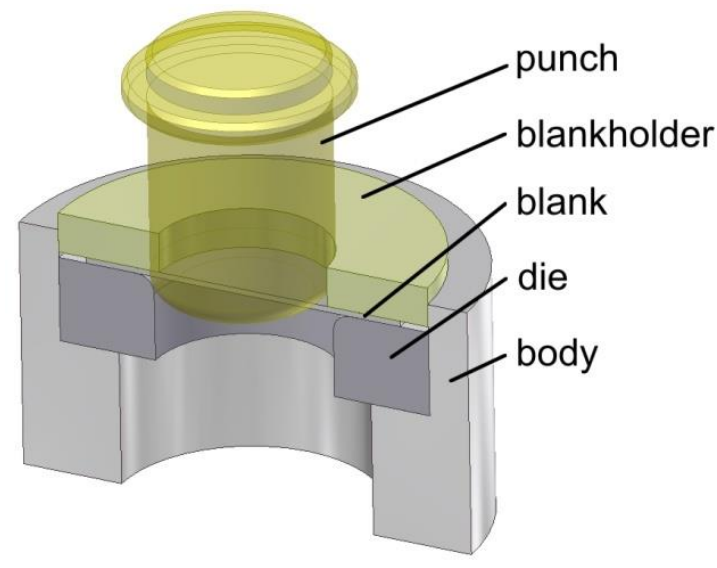

Figure 4: Stamping die: a) pictorial view of the tool, b) schematic of the stamping die.

\section{FINITE ELEMENT MODELLING}

The numerical model was built in ABAQUS/Standard 3D Experience R2016x HF2 finite element code used for the computer-aided analysis of sheet metal forming processes [3, 4]. The dimensions of blank, die and punch correspond to the experimental set-up presented in Figs. 4. As it is commonly used for the analysis of sheet forming, the blank is modelled with 4-node reduced integration, doubly curved, hourglass control C4R shell elements [27, 28]. Five integration points in the thickness direction are used because this is considered sufficient for an acceptable solution [29]. No deformation is assumed because the drawing tools are considered rigid. The tools consist of 22569 4-node bilinear rigid quadrilateral R3D4 shell elements.

A uniform blank holder force of $2 \mathrm{kN}$ was applied on the top surface of a blank holder plate in order to prevent wrinkling. This force value corresponds to that used in the experiment. The boundary conditions applied to the blank holder allow for displacement in the normal direction to the blank surface so that the wrinkling formation is prevented and the frictional resistance in flange region is minimized. The calculations were performed using the implicit finite element code where the internal forces were balanced with the external forces through an iterative procedure, which gave the deformed state after a time increment. One of the merits of this method is that the time increment can be relatively large because of conditional stability of the implicit time integrator and static solutions can be obtained by natural characteristics of the method.

An elastic-plastic material model approach was implemented and anisotropic material with power-type law hardening law (Eq. (1)) have been simulated. In the numerical model, the anisotropy of the material has been established using Hill (1948) [13] yield criterion which can be applied for material description of steel sheet metals. The material behaviour of sheet is specified using the following properties: Young's modulus: $E=2.1 \mathrm{GPa}$, Poisson's ratio $v=0.3$ and mass density $\rho=7860 \mathrm{~kg} \mathrm{~m}^{-3}$. Hill (1948) [13] formulation is the most frequently used yield function in many researches on steel sheet metal forming. The Hill (1948) formulation is an extension of the isotropic von Mises function, and can be expressed in terms of rectangular Cartesian stress components as:

$$
\bar{\sigma}=\sqrt{\left(F\left(\sigma_{22}-\sigma_{33}\right)^{2}+G\left(\sigma_{33}-\sigma_{11}\right)^{2}+H\left(\sigma_{11}-\sigma_{22}\right)^{2}+2 L \sigma_{23}^{2}+2 M \sigma_{31}^{2}+2 N \sigma_{12}^{2}\right.}
$$

where $\bar{\sigma}$ is the equivalent stress, and indices $1,2,3$ represent the rolling, transverse and normal directions to the sheet surface. Constants $F, G, H, L, M$ and $N$ define anisotropy state of material. Axis 1 is parallel to the rolling direction, 2 is parallel to the transverse direction 
and 3 is collinear with the normal direction for sheet metals. If the tensile yield stresses in the principal anisotropy directions are expressed by $X, Y$ and $Z$ then $F, G$ and $H$ terms can be represented by uniaxial yield stresses:

$$
F=\frac{1}{2}\left(\frac{1}{Y^{2}}+\frac{1}{Z^{2}}-\frac{1}{X^{2}}\right), \quad G=\frac{1}{2}\left(\frac{1}{Z^{2}}+\frac{1}{X^{2}}-\frac{1}{Y^{2}}\right), \quad H=\frac{1}{2}\left(\frac{1}{X^{2}}+\frac{1}{Y^{2}}-\frac{1}{Z^{2}}\right)
$$

$R, S$ and $T$ are the shear yield stresses associated to the same directions, then

$$
L=\frac{1}{2 R^{2}}, M=\frac{1}{2 S^{2}}, N=\frac{1}{2 T^{2}},
$$

Only one of the parameters $F, G, H$ can be negative. This situation would cause great differences between the stresses. The relation $F>G$ exists if and only if $X>Y$. Parameters $L$, $M$ and $N$ are always positive. In order to give a complete description of the material anisotropy, the values of six independent yield stresses $(X, Y, Z, R, S$ and $T)$ must be known as well as the orientation of the principal anisotropy axes.

To describe the contact conditions between sheet and tools, the classical friction model following Coulomb's law is assumed in which frictional sliding force is proportional to the applied normal load. The relation between frictional stresses $\tau$ and normal stresses $\sigma$ may be expressed as:

$$
\tau=\mu \sigma
$$

Due to complex formulation, the multi-layer perceptron (MLP) model of the friction coefficient is approximated by simple equation of ellipse where the length of semimajor and semiminor axes of ellipse correspond to the friction coefficient measured in rolling and transverse directions to the rolling direction, respectively. The correlation $R^{2}$ of such approximation is 0.924 . The change of the friction coefficient value as a function of the slip orientation according to the sheet rolling direction in the range of $0^{\circ}$ to $90^{\circ}$ is approximated by Eq. (12):

$$
\begin{aligned}
& \mu_{1}=0.12 \cos \alpha \\
& \mu_{2}=0.15 \sin \alpha
\end{aligned}
$$

where $\alpha$ is an angle between slip direction and rolling direction of the sheet metal, $\alpha \in\left\langle 0^{\circ}, 90^{\circ}\right\rangle$, subscripts 1 and 2 correspond to slip directions where 1 is the rolling direction and 2 is the direction perpendicular to the rolling direction of the sheet metal.

The mesh density is one of the main factors influencing the accuracy of numerical computations. If surface geometry is not well-represented due to the use of a coarse mesh, significant inaccuracies can exist regardless of whether surface-to-surface contact or node-tosurface contact is used [26]. Thus, the mesh sensitivity analysis was carried out. Meshes with different levels of refinement were tested and the results were studied in order to find a mesh that gave accurate results minimizing calculation time.

During analysis of mesh sensitivity, the thinning in the one node located in the symmetry of the process is analysed. Eight mesh densities consisting of 2675 (Fig. 5 a), 3043, 3939, 4548, 5821, 7004, 11424, and 31719 (Fig. 5 b) shell elements were analysed. The computations were carried out using standard 64-bit personal computer (CPU: i7-6700HQ, RAM: 32 GB, HDD: SSD). The effect of mesh density on the value of the predicted sheet thickness at one selected node in the drawpiece bottom centre and the time of computation are presented in Figs. $6 \mathrm{a}$ and $\mathrm{b}$ respectively. The fast increasing of sheet thickness is observed for small number of elements. The larger number of elements, the slower increasing of the thickness value is found. The increasing of the FE elements from 5821 to 7004 elements causes the increasing of the sheet thickness of about 0.16 and $0.1 \%$ for punch depth $11 \mathrm{~mm}$ and full punch penetration, respectively. In this case, the computation time increased to about $27.8 \%$, from 90 to 115 seconds. Further increasing the number of elements to 12000 causes an increase in the predicted sheet thickness of about 0.25 and $0.16 \%$, but the computation 
time increases to $59.2 \%$. The computation time of the model consisted of 31719 S4R elements is equal to 577 seconds. Because the change in predicted sheet thickness is only about $1.5 \%$ compared to the model that consisted of 5821 elements, this mesh density is not acceptable considering the ratio of accuracy to computation time. Nearly linear increasing of the computation time with the increasing the number of elements is observed. After the calculations with different mesh refinements, it was concluded that a mesh with around 5821 elements gives the best comparison between predicted sheet thickness accuracy and computation time.

a)

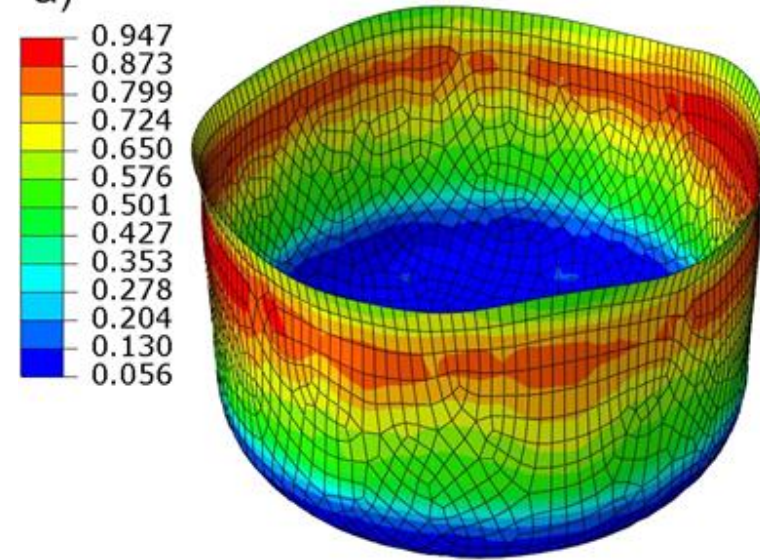

b)

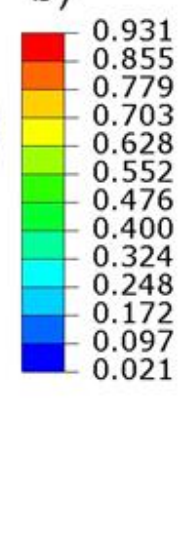

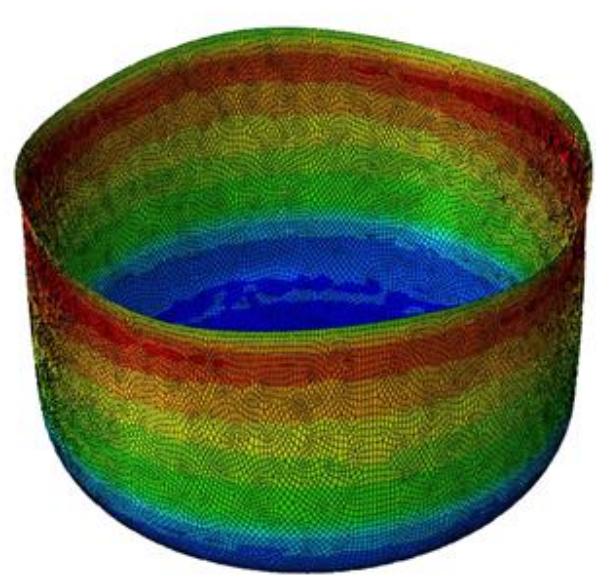

Figure 5: The distribution of plastic strain in drawpieces consisted of a) 2675 shell elements and b) 31719 shell elements.

a)

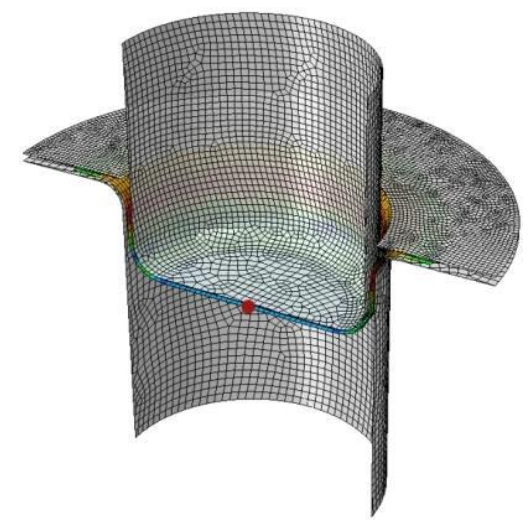

b)

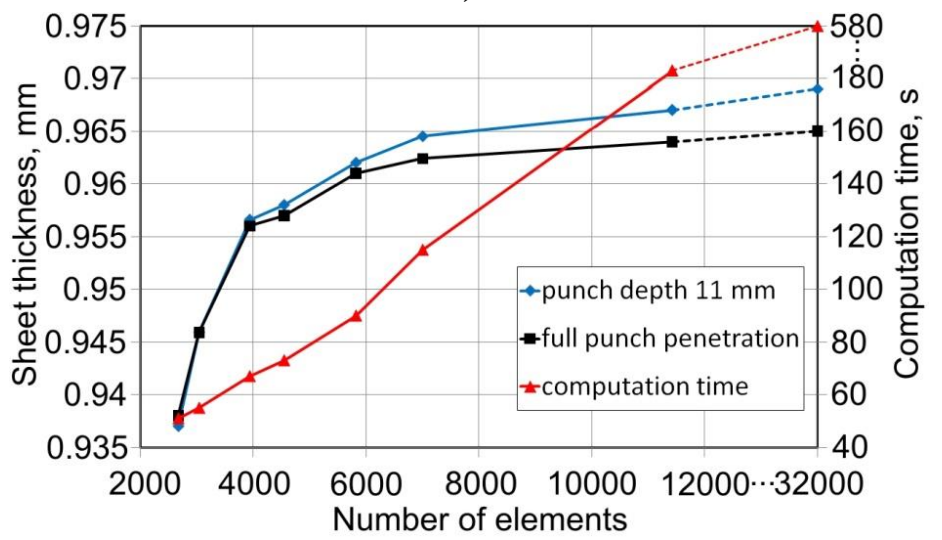

Figure 6: Variation of sheet thickness value as a function of a) location of sheet thickness and b) effect of the number of elements.

\section{RESULTS AND DISCUSSION}

The aim of the conducted numerical simulations was to implement FE model on the anisotropic friction model built using artificial neural network (ANN). How the friction models can affect the height distribution and the influence of frictional anisotropy on the deformation of the cups were considered. The isotropic material model in FE simulation was not considered because the tested sheets exhibit anisotropic mechanical properties. Therefore, the isotropic model of material properties considered in the FE model does not assure the simulation of ears formation.

The simulations were carried out for Hill's material model and two anisotropic elliptic models with different values of friction coefficient measured in the rolling direction (RD) and 
transverse direction (TD): 0.12 and 0.15 , and inversely. Furthermore, to emphasize the effect of frictional anisotropy on the material flow, the following values of friction coefficient were assumed at RD and TD: 0.10 and 0.17 , respectively. The results of the FE models assuming frictional anisotropy were compared with the FE model that includes the isotropic friction model with average friction coefficient of 0.135 . The effect of frictional anisotropy on the sheet thickening and cup flange shape is presented in Fig. 7.

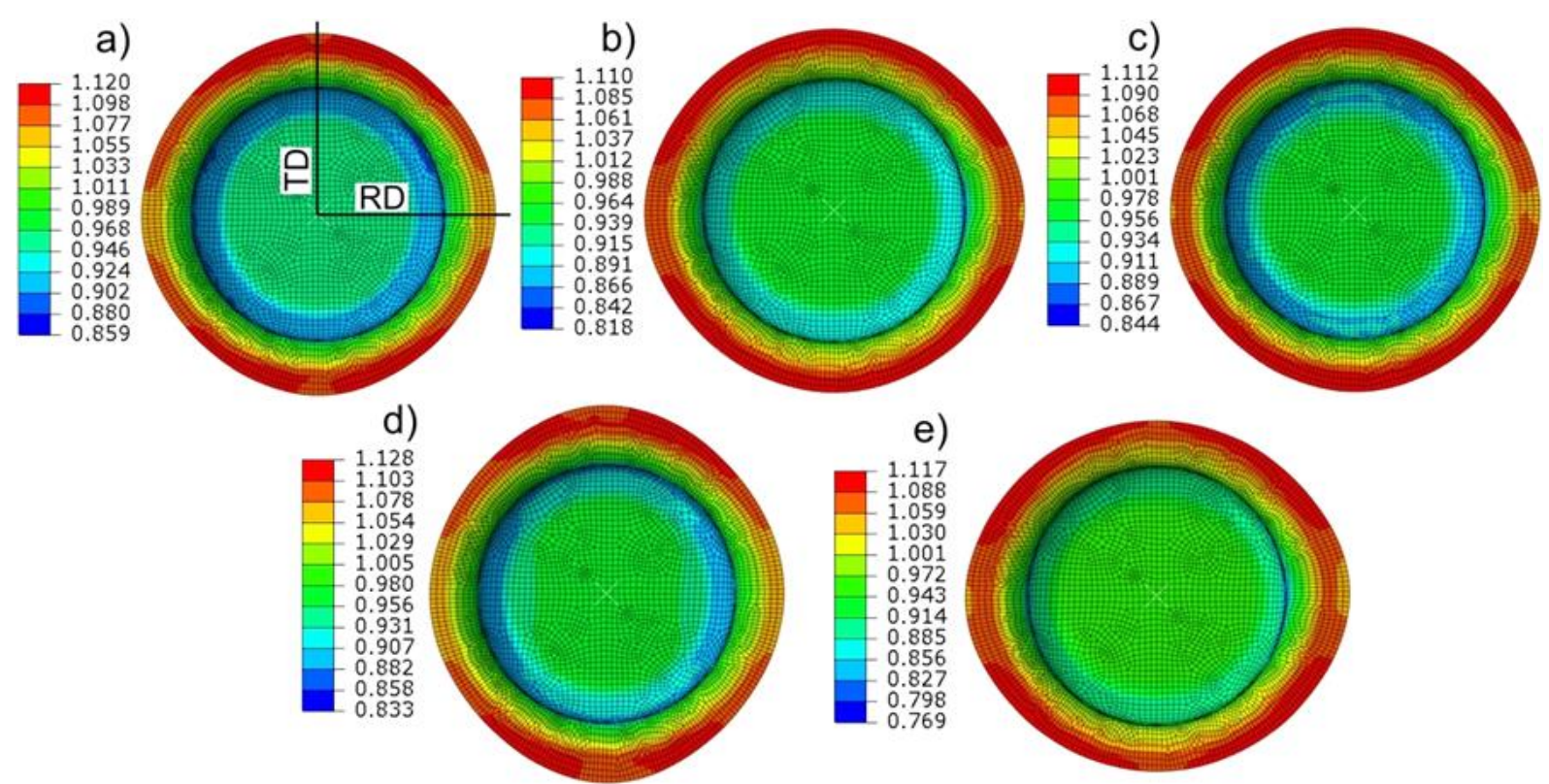

Figure 7: Sheet thickness of drawpiece at punch depth $12.5 \mathrm{~mm}$ for models with the friction coefficients, measured at RD and TD, respectively: a) 0.12 and 0.15, b) 0.15 and 0.12 , c) 0.135, d) 0.10 and 0.17 , and e) 0.17 and 0.10 .

Sheet thickness was measured in symmetry planes of the drawpiece, according to the rolling and transverse directions, starting from the centre of cup bottom. The maximum wall thickness in all directions is observed at the flange region of cup where a high-value compressed circumferential stress exists. The minimum thickness is at the punch shoulder, this region is the most exposed to risk of fracture. The variation of thickness at bottom of drawpiece is relatively small and quite uniform.

The smallest difference between sheet thickness measured at RD and TD is observed for the case when the higher friction coefficient $(0.15)$ is assumed along sheet rolling direction (Fig. 8 a). The contrary friction situation (red lines in Fig. 8 a) causes that the difference between the sheet thickness measured at two perpendicular directions is the highest. Furthermore, the highest difference between analysed friction strategies is observed at the region of contact of the punch corner with internal surface of the cup. However, at cup flange, the difference between thicknesses is quite similar for the three analysed approaches: the sheet thickness measured at TD is higher than that at RD. Material anisotropy has the dominative effect on the circumferential nonuniformity of flange deformation.

Most authors predicted the drawability of anisotropic sheet assuming that the frictional conditions are isotropic. As we found, the assumption of anisotropic friction conditions mostly influences the sheet drawability at the vicinity of contact of punch corner with sheet. The thickening in this location influences reduction of the forming ratio. Due to strain hardening phenomenon, despite the highest thinning in this area, the cup wall is capable of transferring a more and more increased load. Increasing of the punch depth causes that the location of maximum thickening is moved to the end of punch radius (Fig. 8 b). 

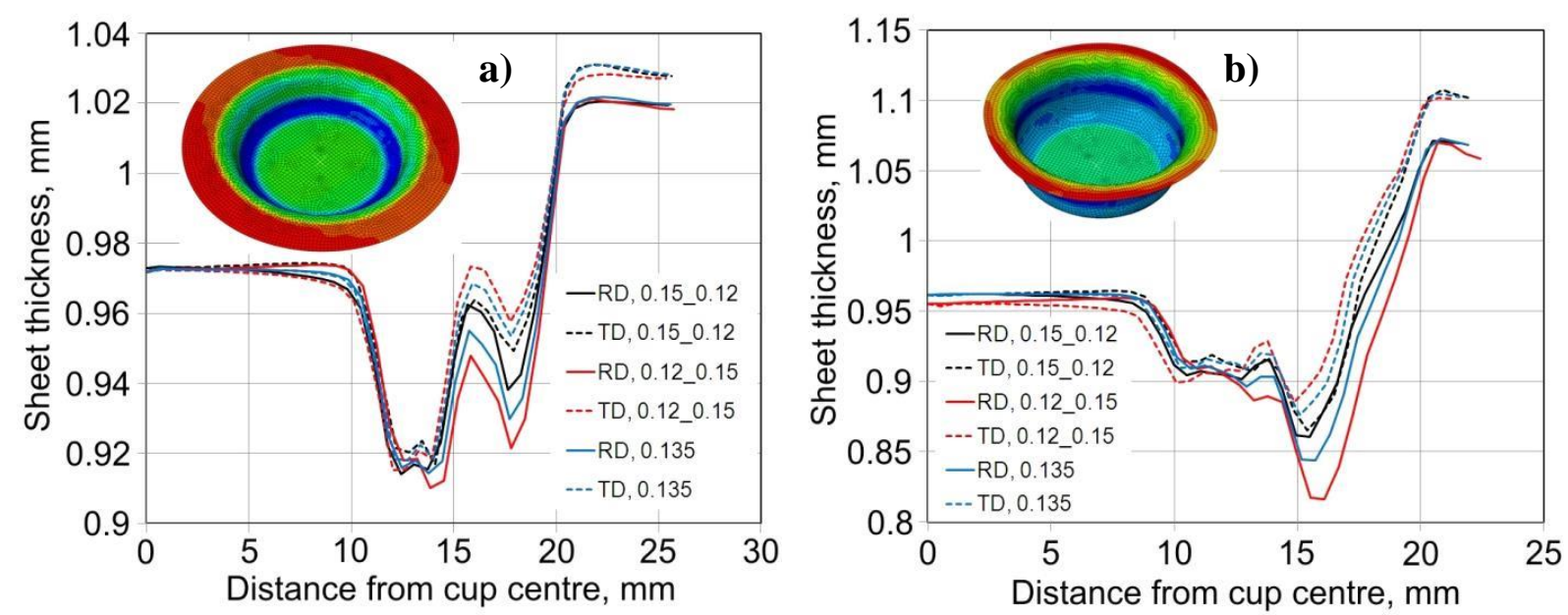

Figure 8: Distribution of sheet thickness at punch depth of a) $6.5 \mathrm{~mm}$ and b) $13 \mathrm{~mm}$.

The comparison between the experimental and numerically predicted cup height for different friction models is presented in Fig. 9. The anisotropic model has taken into account the anisotropy of friction coefficient with the values of 0.12 (RD) and 0.15 (TD). It predicts the best experimental data. Negligible differences can be seen at the location of about $30-45^{\circ}$ and $135-150^{\circ}$. Further, the cup height is overpredicted, which may be due to the fact that numerical simulations also predict a thinner cup's wall than the measured experimental one. In similar investigations $\mathrm{Hu}$ et al. [30] concluded that solid elements, in general, underestimate the extent of thinning. Note that the angular location of the ears for all FE models is nearly the same. Although all the FE models predict the minimum cup height near the angles of $45^{\circ}$ and $135^{\circ}$, orientation of the maximum cup height according to rolling direction $\left(0^{\circ}\right.$ in Fig. 9$)$ depends on the friction phenomena. If the friction coefficient is higher at TD than at RD, the cup height is maximal at the sheet rolling direction $\left(0^{\circ}\right.$ and $180^{\circ}$ in Fig. 9). The assumption of the constant (isotropic) friction phenomena causes that the difference between the cup height measured at RD and TD is the highest.

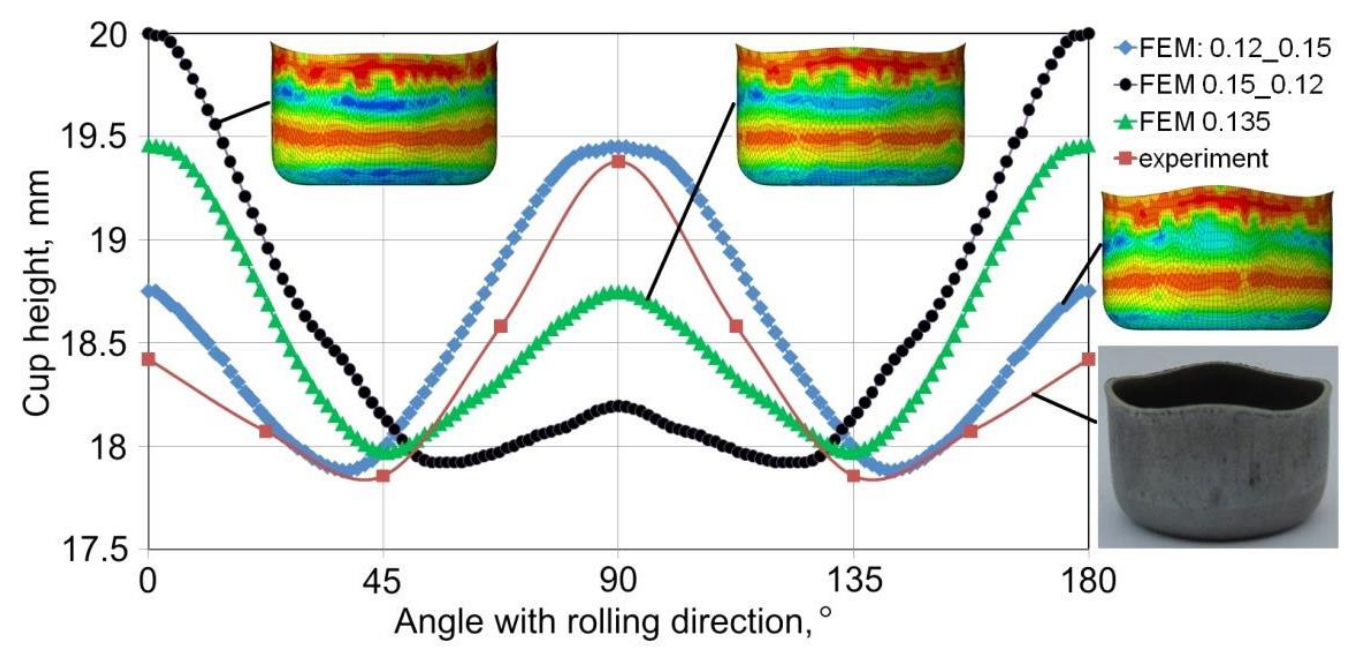

Figure 9: Effect of frictional anisotropy strategy on the ears height.

It can be concluded that, in case of tested anisotropic steel sheets, the assumption of anisotropic material model is insufficient to predict accurately the shape and distribution of ears. The computations indicate that the Hill criterion can be integrated with anisotropic friction model determined experimentally to describe complex behaviour of anisotropic sheet. 
Although the FE predictions are slightly different, they present similar characteristics, i.e. four ears are predicted, but at the different location which depends on the frictional behaviour. However, various process parameters affect the final states of deformation in deep drawing. For instance, punch and die profile radius, sheet thickness, blank-holder force and materials properties [8] are among the important parameters. Our researches also confirm that material model decisively influences the number of ears.

Fig. 10 shows numerical values of the punch force-punch displacement curves for three friction strategies mentioned above. A very good agreement between results has been achieved up to a punch displacement of $15 \mathrm{~mm}$. Some numerical discrepancies appear for the range of penetrations $15-20 \mathrm{~mm}$. They are attributed to the effect of different arrangements and the shape of ears that are pushed to the die hole. After forming of cup, the punch force does not decrease to zero, because the frictional resistances between the die hole and outer cup surface must be overcame. So, it should be noticed that the change in friction slightly influences the maximal punch force value.

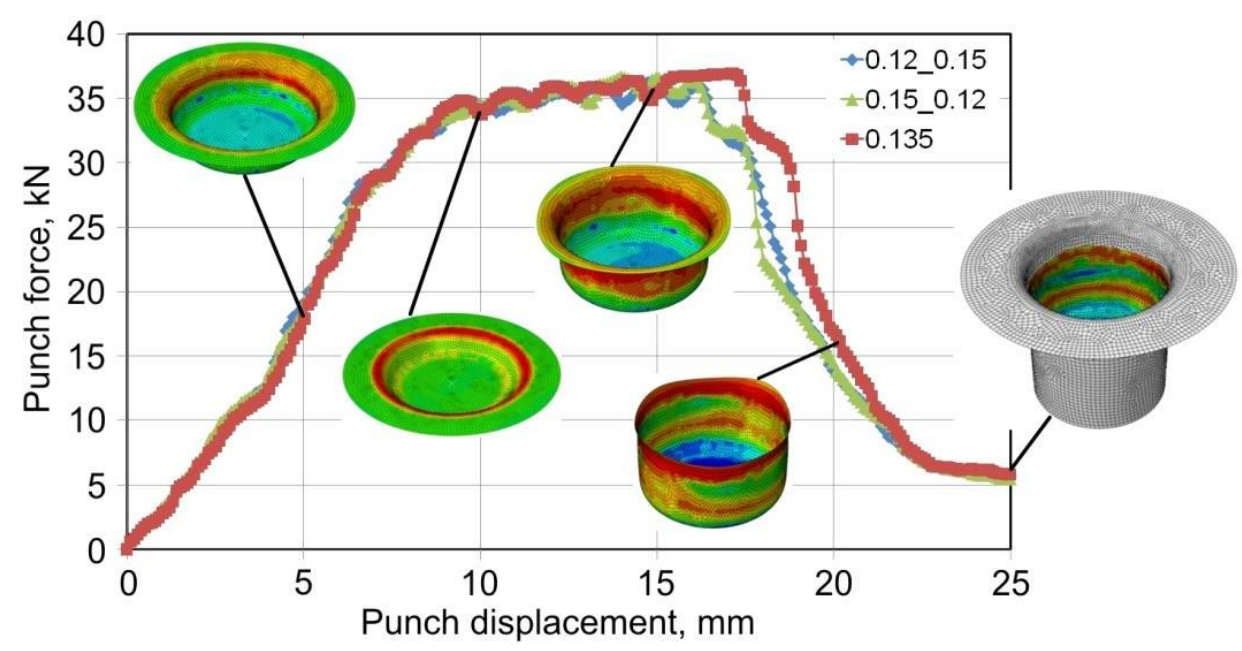

Figure 10: Cylindrical cup drawing test: punch force - punch displacement curve.

\section{CONCLUSIONS}

Material and frictional anisotropy of sheet metals are the main factors that determine high conformity of the finite-element based numerical simulation results with the reality. The following conclusions can be drawn based on the experimental and numerical investigations of cylindrical cup forming:

- the tested rolled deep-drawing steel sheet is characterized by directional topography, which influences the change of the friction coefficient ad perpendicular directions: RD and TD,

- the frictional anisotropy affects the location and height of ears,

- consideration of the anisotropy of resistance to friction slightly influences the numerical results on variation of the punch force,

- the ears location prediction in the case of isotropic friction indicates that the effect of the friction formulation is relatively small in comparison with material anisotropy,

- the mesh sensitivity analysis shows that the larger number of elements the slower increasing of the predicted thickness value is observed,

- nearly linear increasing of the computation time with the increasing the number of elements is observed,

- the maximum cup height is overpredicted by all analysed approaches; it is also confirmed by $\mathrm{Hu}$ et al. [30] who studied the solid elements. 
Continuing future works will focus on verification of obtained numerical results for their ability to correctly predict the cup height distribution during forming of different materials. The anisotropic friction model sensitivity of the cup height and thickness distributions should also be verified for different drawing ratios. In addition, to what extent the strongly integrated material anisotropy with frictional anisotropy is sensitive to the change in the frictional behaviour of deformed shape is studied.

\section{REFERENCES}

[1] Li, M.-Z.; Cai, Z.-Y., Liu, C.-G. (2007). Flexible manufacturing of sheet metal parts based on digitized-die, Robotics and Computer-Integrated Manufacturing, Vol. 23, No. 1, 107-115, doi:10.1016/j.rcim.2005.09.005

[2] Mantaras, D. A.; Luque, P. (2015). Assessing motorcyclist protection systems using finite element simulations, International Journal of Simulation Modelling, Vol. 14, No. 1, 110-120, doi:10.2507/IJSIMM14(1)10.294

[3] Trzepieciński, T.; Gelgele, H. L. (2011). Investigation of anisotropy problems in sheet metal forming using finite element method, International Journal of Material Forming, Vol. 4, No. 4, 357-369, doi:10.1007/s12289-010-0994-7

[4] Lemu, H. G.; Trzepieciński, T. (2012). FEM based deformability analysis of metal forming: Influence of material models and analysis approaches, AIP Conference Proceedings, Vol. 1431, No. 1, 702-710, doi:10.1063/1.4707626

[5] Marciniak, Z.; Hu, S. J.; Duncan, J. L. (2002). Mechanics of Sheet Metal Forming, ButterworthHeinemann, Oxford

[6] Dilmec, M.; Halkaci, H. S.; Ozturk F.; Turkoz, M. (2013). Effect of sheet thickness on the anisotropy and thickness distribution for AA2024-T4, Materiali in tehnologije - Materials and Technology, Vol. 47, No. 5, 605-610

[7] Chung, K.; Kim, D.; Park, T. (2011). Analytical derivation of earing in circular cup drawing based on simple tension properties, European Journal of Mechanics - A/Solids, Vol. 30, No. 3, 275-280, doi:10.1016/j.euromechsol.2011.01.006

[8] Saxena, R. K.; Dixit, P. M. (2009). Finite element simulation of earing defect in deep drawing, International Journal of Advanced Manufacturing Technology, Vol. 45, No. 3-4, 219-233, doi:10.1007/s00170-009-1963-5

[9] Hamada, J.; Agata, K.; Inoue, H. (2009). Estimation of planar anisotropy of the $r$-value in ferritic stainless steel sheets, Materials Transactions, Vol. 50, No. 4, 752-758, doi:10.2320/ matertrans.MRA2008399

[10] Dezelak, M.; Stepisnik, A.; Pahole, I.; Ficko, M. (2014). Evaluation of twist springback prediction after an AHSS forming process, International Journal of Simulation Modelling, Vol. 13, No. 2, 171-182, doi:10.2507/IJSIMM13(2)4.261

[11] Neto, D. M.; Oliveira, M. C.; Alves, J. L.; Menezes, L. F. (2014). Influence of the plastic anisotropy modelling in the reverse deep drawing process simulation, Materials \& Design, Vol. 60, 368-379, doi:10.1016/j.matdes.2014.04.008

[12] Abed-Meraim, F.; Wang, P.; Chalal, H. (2017). Linear and quadratic solid-shell elements for quasi-static and dynamic simulations of thin 3D structures: Application to a deep drawing process, Strojniski vestnik - Journal of Mechanical Engineering, Vol. 63, No. 1, 25-34, doi: $10.5545 /$ sv-jme.2016.3526

[13] Hill, R. (1948). A theory of the yielding and plastic flow of anisotropic metals, Proceedings of the Royal Society A, Vol. 193, No. 1033, 281-297, doi:10.1098/rspa.1948.0045

[14] Hosford, W. F. (1972). A generalized isotropic yield criterion, Journal of Applied Mechanics, Vol. 39, No. 2, 607-609, doi:10.1115/1.3422732

[15] von Mises, R. (1913). Mechanik der festen Körper im plastisch deformablen Zustand, Nachrichten von der Gesellschaft der Wissenschaften zu Göttingen, Mathematisch-Physikalische Klasse, Vol. 1913, 582-592 
[16] Tikhovskiy, I.; Raabe, D.; Roters, F. (2008). Simulation of earing of a $17 \%$ Cr stainless steel considering texture gradients, Materials Science and Engineering: A, Vol. 488, No. 1-2, 482-490, doi:10.1016/j.msea.2007.11.063

[17] Shafaat, M. A.; Abbasi, M.; Ketabchi, M. (2011). Investigation into wall wrinkling in deep drawing process of conical cups, Journal of Materials Processing Technology, Vol. 211, No. 11, 1783-1795, doi:10.1016/j.jmatprotec.2011.05.026

[18] Raabe, D.; Wang, Y.; Roters, F. (2005). Crystal plasticity simulation study on the influence of texture on earing in steel, Computational Materials Science, Vol. 34, No. 3, 221-234, doi:10.1016/j.commatsci.2004.12.072

[19] Tikhovskiy, I.; Raabe, D.; Roters, F. (2007). Simulation of earing during deep drawing of an Al$3 \% \mathrm{Mg}$ alloy (AA 5754) using a texture component crystal plasticity FEM, Journal of Materials Processing Technology, Vol. 183, No. 2-3, 169-175, doi:10.1016/j.jmatprotec.2006.10.006

[20] Lin, C.-T.; Kwan, C.-T. (2009). Application of abductive network and FEM to predict the optimal blank contour of an elliptic cylindrical cup from deep drawing, Journal of Materials Processing Technology, Vol. 209, No. 3, 1351-1361, doi:10.1016/j.jmatprotec.2008.03.042

[21] Habraken, A. M.; Duchêne, L. (2004). Anisotropic elasto-plastic finite element analysis using a stress-strain interpolation method based on a polycrystalline model, International Journal of Plasticity, Vol. 20, No. 8-9, 1525-1560, doi:10.1016/j.ijplas.2003.11.006

[22] Wang, D.; Yang, H.; Li, H. (2014). Advance and trend of friction study in plastic forming, Transactions of Nonferrous Metals Society of China, Vol. 24, No. 5, 1263-1272, doi:10.1016/ S1003-6326(14)63188-5

[23] Trzepieciński, T.; Lemu, H. G. (2014). Frictional conditions of AA5251 aluminium alloy sheets using drawbead simulator tests and numerical methods, Strojniski vestnik - Journal of Mechanical Engineering, Vol. 60, No. 1, 51-60, doi:10.5545/sv-jme.2013.1310

[24] Lemu, H. G.; Trzepieciński, T. (2013). Numerical and experimental study of frictional behavior in bending under tension test, Strojniski vestnik - Journal of Mechanical Engineering, Vol. 59, No. 1, 41-49, doi: 10.5545/sv-jme.2012.383

[25] Ajayi, O. O.; Erck, R. A.; Lorenzo-Martin, C.; Fenske, G. R. (2009). Frictional anisotropy under boundary lubrication: Effect of surface texture, Wear, Vol. 267, No. 5-8, 1214-1219, doi:10.1016/j.wear.2008.12.106

[26] Sedlaček, M.; Vilhena, L. M. S.; Podgornik, B.; Vižintin, J. (2011). Surface topography modeling for reduced friction, Strojniski vestnik - Journal of Mechanical Engineering, Vol. 57, No. 9, 674680, doi: $10.5545 / \mathrm{sv}$-jme. 2010.140

[27] ABAQUS 2016 (2015). Abaqus Theory Guide, Dassault Systèmes, Hibbit

[28] Yamashita, M.; Khalil, Z. B. (2015). Deformation behavior of press formed shell by indentation and its numerical simulation, Journal of Engineering, Vol. 2015, article ID 453931, 11 pages, doi:10.1155/2015/453931

[29] Larsson, M. (2009). Computational characterization of drawbeads: A basic modeling method for data generation, Journal of Materials Processing Technology, Vol. 209, No. 1, 376-386, doi:10.1016/j.jmatprotec.2008.02.009

[30] Hu, J. G.; Jonas, J. J.; Ishikawa, T. (1998). FEM simulation of the forming of textured aluminium sheets, Materials Science and Engineering: A, Vol. 256, No. 1-2, 51-59, doi:10.1016/S0921$\underline{5093(98) 00813-2}$ 